\title{
Arctic Ocean data in CARINA
}

\author{
S. Jutterström ${ }^{1}$, L. G. Anderson ${ }^{1}$, N. R. Bates ${ }^{2}$, R. Bellerby ${ }^{3,4}$, T. Johannessen ${ }^{4,3}$, E. P. Jones ${ }^{5}$, R. M. Key ${ }^{6}$, \\ X. Lin $^{6}$, A. Olsen ${ }^{4,3,1}$, and A. M. Omar ${ }^{3,4}$ \\ ${ }^{1}$ Department of Chemistry, University of Gothenburg, Gothenburg, Sweden \\ ${ }^{2}$ Bermuda Biological Station for Research Inc., St. George's GE01, Bermuda \\ ${ }^{3}$ Bjerknes Centre for Climate Research, UNIFOB AS, Bergen, Norway \\ ${ }^{4}$ Geophysical Institute, University of Bergen, Bergen, Norway \\ ${ }^{5}$ Bedford Institute of Oceanography; Department of Fisheries and Oceans, Dartmouth, Nova Scotia, Canada \\ ${ }^{6}$ Atmospheric and Oceanic Sciences Program; Princeton University, Princeton, NJ 08544, USA
}

Received: 21 June 2009 - Published in Earth Syst. Sci. Data Discuss.: 21 August 2009

Revised: 12 January 2010 - Accepted: 14 January 2010 - Published: 10 February 2010

\begin{abstract}
The paper describes the steps taken for quality controlling chosen parameters within the Arctic Ocean data included in the CARINA data set and checking for offsets between the individual cruises. The evaluated parameters are the inorganic carbon parameters (total dissolved inorganic carbon, total alkalinity and $\mathrm{pH}$ ), oxygen and nutrients: nitrate, phosphate and silicate. More parameters can be found in the CARINA data product, but were not subject to a secondary quality control. The main method in determining offsets between cruises was regional multi-linear regression, after a first rough basin-wide deep-water estimate of each parameter. Lastly, the results of the secondary quality control are discussed as well as applied adjustments.
\end{abstract}

\section{Data coverage and parameter measured}

Repository-Reference:

doi:10.3334/CDIAC/otg.CARINA.AMS.V1.2

Available at:

http://cdiac.ornl.gov/ftp/oceans/CARINA/CARINA_

Database/CARINA.AMS.V1.2/

Coverage: $60 \mathrm{~N}$ to $90 \mathrm{~N}$ and circumpolar $\left(0-360^{\circ}\right)$

Location Name: Arctic Ocean

Date/Time Start: 1980-08-11

Date/Time End: 2005-05-20

\section{Introduction}

The CARINA data set contains 28 cruises collected in the Arctic Ocean, in the Arctic Ocean shelf seas including the Barents Sea and in the Canadian Arctic Archipelago (Table 1). For further information (e.g. responsible scientists, references etc.) about the individual cruises, the reader is referred to the following site: http://cdiac.ornl.gov/oceans/ CARINA/Carina_table.html.

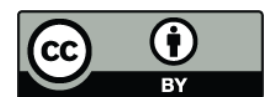

Correspondence to: S. Jutterström (sara.jutterstrom@chem.gu.se)
The oldest data is from 1980 (77YM19800811) with the Swedish icebreaker Ymer and the latest is a Barents Sea cruise in 2005 (58JM20050520) with a Norwegian ship Jan Mayen. The parameters discussed in this paper include the carbon parameters (total dissolved inorganic carbon $\left(\mathrm{TCO}_{2}\right)$, total alkalinity (TA) and $\mathrm{pH}$ ), oxygen $\left(\mathrm{O}_{2}\right)$ and nutrients (nitrate $\left(\mathrm{NO}_{3}\right)$, phosphate $\left(\mathrm{PO}_{4}\right)$ and silicate $\left.(\mathrm{Si})\right)$. However more parameters may be included in the data product itself. For the CFCs the reader is referred to the paper of Jeansson et al. (2009) describing the analyses of the Arctic Ocean and Nordic Seas CFCs.

\section{Determining offsets between cruises}

The difficulty of investigating the Arctic data is that the cruises are quite few and spread out both in time and location. Also, the separate basins show differences in the N/P ratios, Si concentrations, and oxygen saturation in the deepwater etc. Therefore, the investigations have been done for each individual basin of the Arctic Ocean. The disadvantage of this is of course that the scarcity of data makes it very difficult to quickly see which cruise is offset when there are only two or three others for comparison. Figure 1 shows the locations of all stations with the stations included in the secondary QC marked red. 
Table 1. Cruises and parameters included in the Arctic Ocean synthesis in CARINA listed together with the number of stations and samples (flagged 2 in the CARINA.AMS.V1.2). Note that the number of stations and samples can differ from the ones in the Carina table at CDIAC for that reason.

\begin{tabular}{|c|c|c|c|c|c|c|c|c|c|c|c|}
\hline Cruise \# & EXPOCODE & AREA & $\begin{array}{l}\text { \# stations } \\
\text { (\# samples) }\end{array}$ & $\mathrm{TCO}_{2}$ & $\mathrm{TA}$ & $\begin{array}{l}\text { CRMs } \\
\text { used: }\end{array}$ & $\mathrm{pH}$ & $\mathrm{NO}_{3}$ & $\mathrm{PO}_{4}$ & $\mathrm{Si}$ & $\mathrm{O}_{2}$ \\
\hline 2 & 06AQ19930806 & Central Arctic & $64(1273)$ & $63(1087)$ & NA & NA & NA & $63(1083)$ & $64(1109)$ & $64(1103)$ & $64(1126)$ \\
\hline 3 & 06AQ19960712 & Central Arctic & $102(2481)$ & 78 (1216) & 62 (915) & Yes & $82(1264)$ & $102(2410)$ & $102(2421)$ & $102(2359)$ & $102(2431)$ \\
\hline 45 & 18RD19980404 ${ }^{\mathrm{a}}$ & North Water Polynya & $348(6757)$ & $72(737)$ & $63(567)$ & Yes & NA & $133(1364)$ & $123(1275)$ & $129(1182)$ & $64(661)$ \\
\hline 46 & 18RD19990827 & North Water Polynya & $40(464)$ & $40(387)$ & $40(316)$ & Yes & NA & NA & NA & NA & NA \\
\hline 47 & 18 SN19940724 & Central Arctic & $39(1269)$ & $39(1021)$ & $38(914)$ & Yes & NA & $38(1084)$ & $39(1087)$ & $38(1034)$ & $39(1056)$ \\
\hline 48 & 18SN19970803 & Canadian Arctic Archipelago & $24(424)$ & $24(327)$ & $24(326)$ & Yes & NA & $24(352)$ & $24(356)$ & $24(356)$ & $24(353)$ \\
\hline 49 & 18SN19970831 & Canadian Arctic Archipelago & $26(379)$ & $26(328)$ & $26(298)$ & Yes & NA & NA & NA & NA & NA \\
\hline 50 & 18SN19970924 & Central Arctic & $16(475)$ & $16(352)$ & $16(319)$ & Yes & NA & $16(452)$ & $16(452)$ & $16(452)$ & $16(475)$ \\
\hline 72 & $32 \mathrm{H} 120020505^{\mathrm{a}}$ & Central Arctic & $36(1579)$ & $28(330)$ & $28(330)$ & Yes & NA & $35(778)$ & $35(778)$ & $35(767)$ & $34(528)$ \\
\hline 73 & $32 \mathrm{H} 120020718$ & Central Arctic & $44(1857)$ & $42(472)^{\mathrm{c}}$ & NA & Yes & NA & $44(861)$ & $44(861)$ & $44(861)$ & $44(721)$ \\
\hline 74 & $32 \mathrm{H} 120030911^{\mathrm{a}}$ & Central Arctic & $186(1197)$ & NA & NA & & NA & $162(937)$ & $167(961)$ & $167(959)$ & $152(810)$ \\
\hline 75 & $32 \mathrm{H} 120040515^{\mathrm{a}}$ & Central Arctic & $35(1116)$ & $31(308)$ & $31(305)$ & Yes & NA & $35(588)$ & $35(588)$ & $35(590)$ & $35(455)$ \\
\hline 76 & $32 \mathrm{H} 120040718^{\mathrm{a}}$ & Central Arctic & $60(2155)$ & $56(469)$ & $55(453)$ & Yes & NA & $60(1309)$ & $60(1310)$ & $60(1311)$ & $60(972)$ \\
\hline 77 & $32 \mathrm{H} 120040910$ & Central Arctic & $117(1555)$ & NA & NA & & NA & $113(829)$ & $113(833)$ & $113(833)$ & $113(782)$ \\
\hline 82 & $32 \mathrm{PZ20020715}$ & Central Arctic & $63(506)$ & NA & NA & & NA & $59(474)$ & $63(494)$ & $63(495)$ & NA \\
\hline 83 & 320620030705 & Central Arctic & $326(3642)$ & NA & NA & & NA & $326(3446)$ & $326(3446)$ & $326(3444)$ & $326(3427)$ \\
\hline 123 & 58AA19991003 & Storfjorden & $71(374)$ & $61(286)$ & $59(275)$ & Yes & NA & $71(369)$ & $71(366)$ & $71(372)$ & NA \\
\hline 124 & 58AA20000923 & Storfjorden & $168(502)$ & $168(500)$ & $168(493)$ & Yes & NA & $168(498)$ & $167(496)$ & $168(499)$ & $168(492)$ \\
\hline 126 & $58 \mathrm{AA} 20010822^{\mathrm{a}}$ & Storfjorden & $69(266)$ & $68(261)$ & $68(256)$ & Yes & NA & NA & NA & NA & $69(259)$ \\
\hline 145 & $58 \mathrm{JM} 20030710^{\mathrm{a}}$ & Barents Sea & $4(258)$ & $4(253)$ & $4(203)$ & Yes & NA & $4(246)$ & $4(244)$ & $4(245)$ & NA \\
\hline 146 & 58JM20040724 & Barents Sea & $7(79)$ & $7(79)$ & $5(56)$ & Yes & NA & $7(76)$ & $7(78)$ & $7(78)$ & NA \\
\hline 147 & 58JM20050520 & Barents Sea & $9(106)$ & $9(104)$ & $9(101)$ & Yes & NA & $9(104)$ & $9(104)$ & $9(105)$ & NA \\
\hline 148 & 58LA19860719 & Barents Sea & $11(55)$ & $7(33)$ & $7(31)$ & No & 11 (53) Titrated & $11(55)$ & $9(41)$ & $11(55)$ & $11(55)$ \\
\hline 177 & 77DN19910726 & Central Arctic & $54(1618)$ & 45 (1103) & $44(1121)$ & No & NA & $54(1599)$ & $49(1482)$ & $53(1585)$ & $54(1502)$ \\
\hline 178 & 77DN20010717 & Central Arctic & \multicolumn{9}{|c|}{ Cruise not included in the final synthesis, data consists of alkalinity data (samples were stored and analysed on shore) } \\
\hline 179 & 77DN20020420 b & Nordic Seas & $92(1569)$ & $91(1384)$ & $92(1498)$ & Yes & $92(1503)$ & $92(1564)$ & $92(1564)$ & $92(1565)$ & $92(1546)$ \\
\hline 180 & 77YM19800811 & Central Arctic & $63(1072)$ & NA & NA & & NA & Nutrients no & included in $\mathrm{tl}$ & e synthesis & $22(240)$ \\
\hline 181 & 90AQ19940706 & Central Arctic & 75 (137) & $14(69)$ & $29(91)$ & NA & NA & NA & NA & $29(91)$ & $16(76)$ \\
\hline
\end{tabular}

a These cruises have been through primary QC and are in the data product, but they have not been through the repeated primary QC or the secondary QC

${ }^{\mathrm{b}}$ One section in the Fram Strait was used for comparisons, for more details of this cruise see Olsen (2009).

c Samples were stored and analysed on shore.

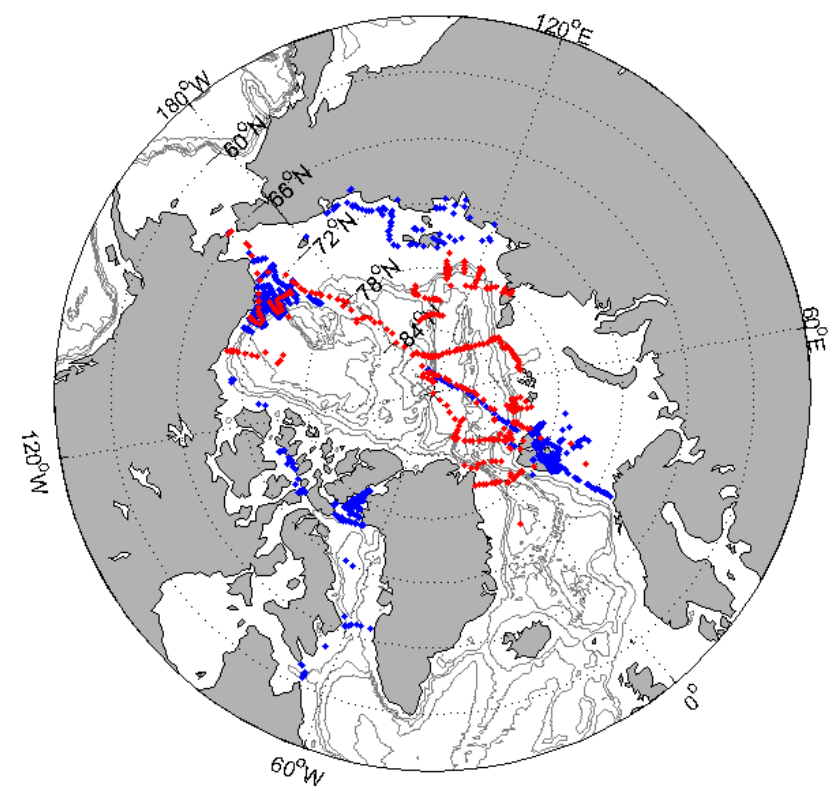

Figure 1. Map of all station locations of cruises included in Table 1, all station locations of the cruises included in the secondary QC are labelled red.
Many, but not all, cruises were investigated in a repeat primary QC fashion, which included examination of depth profiles, property-property plots etc. To see which cruises were not involved repeated primary QC see Table 1. However, only cruises with station depths deeper than $2500 \mathrm{~m}$ were involved in the secondary QC. This unfortunately excluded all except 8 cruises and left out many of the shelf cruises that did not have a section extending into the central basin, but these shallower waters show too much variability to make it possible to determine reliable offsets.

As a first step, deep-water averages of each parameter were calculated for every separate basin in the Arctic Ocean (Fig. 2) for each of the 8 cruises included in the secondary QC (Table 2). This was also done to look at the spread of each parameter in the deep-water. The results show that there likely existed an offset between some of the parameters in different cruises. However, deep-water averages does not take into consideration the natural variability of water masses and other processes and a supplementary method to confirm the offsets found in the deep-water averages was sought.

Crossovers between the Arctic cruises were carried out using the manual approach described by Tanhua et al. (2009), with modifications according to Olsen et al. (2009). 
Table 2. Deep-water averages (depth $>2500 \mathrm{~m}$ ).

\begin{tabular}{|c|c|c|c|c|c|c|c|c|c|c|c|}
\hline Cruise \# & EXPOCODE & $\mathrm{TCO}_{2}$ & $\mathrm{TCO}_{2}-35^{\mathrm{a}}$ & TA & $\mathrm{TA}-35^{\mathrm{a}}$ & $\mathrm{pH}$ & $\mathrm{O} 2$ & $\mathrm{NO}_{3}$ & $\mathrm{PO}_{4}$ & $\mathrm{Si}$ & Sal \\
\hline 50 & $\begin{array}{l}\text { Canada Basin: } \\
\text { 18SN19970924 }\end{array}$ & $2154 \pm 3$ & $2157 \pm 3$ & $2299 \pm 5$ & $2302 \pm 5$ & $\mathrm{NaN}$ & $278.3 \pm 2.6$ & $14.3 \pm 0.1$ & $1.02 \pm 0.01$ & $13.4 \pm 0.5$ & $34.9554 \pm 0.0013$ \\
\hline 73 & $\begin{array}{l}\text { 32H120020718 } \\
\text { Makarov Basin: }\end{array}$ & $2149 \pm 1$ & $2152 \pm 1$ & $\mathrm{NaN}$ & $\mathrm{NaN}$ & $\mathrm{NaN}$ & $285.0 \pm 1.3$ & $14.5 \pm 0.1$ & $1.03 \pm 0.01$ & $13.2 \pm 0.5$ & $34.9549 \pm 0.0013$ \\
\hline 3 & 06AQ19960712 & $2148 \pm 2$ & $2150 \pm 2$ & $2296 \pm 2$ & $2299 \pm 2$ & $7.860 \pm 0.003$ & $287.6 \pm 1.6$ & $13.8 \pm 0.1$ & $1.00 \pm 0.02$ & $12.6 \pm 0.3$ & $34.9519 \pm 0.0015$ \\
\hline 47 & 18SN19940724 & $2159 \pm 3$ & $2162 \pm 3$ & $2328 \pm 4$ & $2331 \pm 4$ & $\mathrm{NaN}$ & $288.7 \pm 0.9$ & $14.5 \pm 0.04$ & $1.04 \pm 0.01$ & $13.4 \pm 0.3$ & $34.9531 \pm 0.0007$ \\
\hline 177 & $\begin{array}{l}\text { 77DN19910726 } \\
\text { Amundsen Basin: }\end{array}$ & $2157 \pm 2$ & $2160 \pm 2$ & $2289 \pm 7$ & $2292 \pm 7$ & $\mathrm{NaN}$ & $293.2 \pm 1.3$ & $14.8 \pm 0.07$ & $0.99 \pm 0.004$ & $11.9 \pm 0.2$ & $34.9544 \pm 0.0016$ \\
\hline 3 & 06AQ19960712 & $2153 \pm 8$ & $2157 \pm 8$ & $2298 \pm 3$ & $2302 \pm 3$ & $7.856 \pm 0.004$ & $298.8 \pm 0.8$ & $13.7 \pm 0.2$ & $0.97 \pm 0.02$ & $11.1 \pm 0.2$ & $34.9377 \pm 0.0054$ \\
\hline 47 & 18SN19940724 & $2163 \pm 2$ & $2167 \pm 2$ & $2326 \pm 2$ & $2330 \pm 2$ & $\mathrm{NaN}$ & $299.2 \pm 0.5$ & $14.5 \pm 0.07$ & $1.03 \pm 0.01$ & $12.2 \pm 0.2$ & $34.9339 \pm 0.006$ \\
\hline 177 & $\begin{array}{l}\text { 77DN19910726 } \\
\text { Nansen Basin: }\end{array}$ & $2149 \pm 5$ & $2154 \pm 5$ & $2291 \pm 11$ & $2295 \pm 12$ & $\mathrm{NaN}$ & $302.1 \pm 2.0$ & $14.5 \pm 0.1$ & $0.97 \pm 0.01$ & $10.9 \pm 0.2$ & $34.9361 \pm 0.0064$ \\
\hline 2 & 06AQ19930806 & $2150 \pm 3$ & $2154 \pm 3$ & $\mathrm{NaN}$ & $\mathrm{NaN}$ & $\mathrm{NaN}$ & $278.9 \pm 1.7$ & $13.6 \pm 0.4$ & $0.97 \pm 0.06$ & $11.4 \pm 0.4$ & $34.9327 \pm 0.0052$ \\
\hline 3 & 06AQ19960712 & $2155 \pm 3$ & $2159 \pm 3$ & $\mathrm{NaN}$ & $\mathrm{NaN}$ & $7.855 \pm 0.005$ & $298.5 \pm 1.3$ & $14.3 \pm 0.3$ & $0.97 \pm 0.02$ & $11.3 \pm 0.3$ & $34.9381 \pm 0.0047$ \\
\hline 47 & 18SN19940724 & $2159 \pm 2$ & $2163 \pm 2$ & $2320 \pm 4$ & $2324 \pm 4$ & $\mathrm{NaN}$ & $298.9 \pm 1.1$ & $14.5 \pm 0.04$ & $1.03 \pm 0.01$ & $12.9 \pm 0.3$ & $34.9374 \pm 0.0031$ \\
\hline 177 & $\begin{array}{l}\text { 77DN19910726 } \\
\text { Fram Strait: }\end{array}$ & $2153 \pm 4$ & $2157 \pm 4$ & $2298 \pm 7$ & $2302 \pm 6$ & $\mathrm{NaN}$ & $299.3 \pm 2.6$ & $14.7 \pm 0.2$ & $0.98 \pm 0.02$ & $11.1 \pm 0.2$ & $34.9399 \pm 0.0044$ \\
\hline 179 & 77DN20020420 & $2149 \pm 3$ & $2153 \pm 3$ & $2304 \pm 4$ & $2308 \pm 3$ & $7.885 \pm 0.005$ & $302.4 \pm 2.0$ & $14.7 \pm 0.1$ & $0.97 \pm 0.02$ & $10.7 \pm 0.1$ & $34.9314 \pm 0.0074$ \\
\hline 180 & 77YM19800811 & $\mathrm{NaN}$ & $\mathrm{NaN}$ & $\mathrm{NaN}$ & $\mathrm{NaN}$ & $\mathrm{NaN}$ & $303.2 \pm 4.9$ & $12.3 \pm 0.2$ & $0.86 \pm 0.03$ & $10.3 \pm 0.7$ & $34.9313 \pm 0.0111$ \\
\hline
\end{tabular}

${ }^{\text {a }}$ Data is normalised to a salinity of $35, \mathrm{TCO}_{2}-35=\mathrm{TCO}_{2} \cdot 35 / \mathrm{S}$ alt. TA-35 $=\mathrm{TA} \cdot 35 / \mathrm{Sal}$.

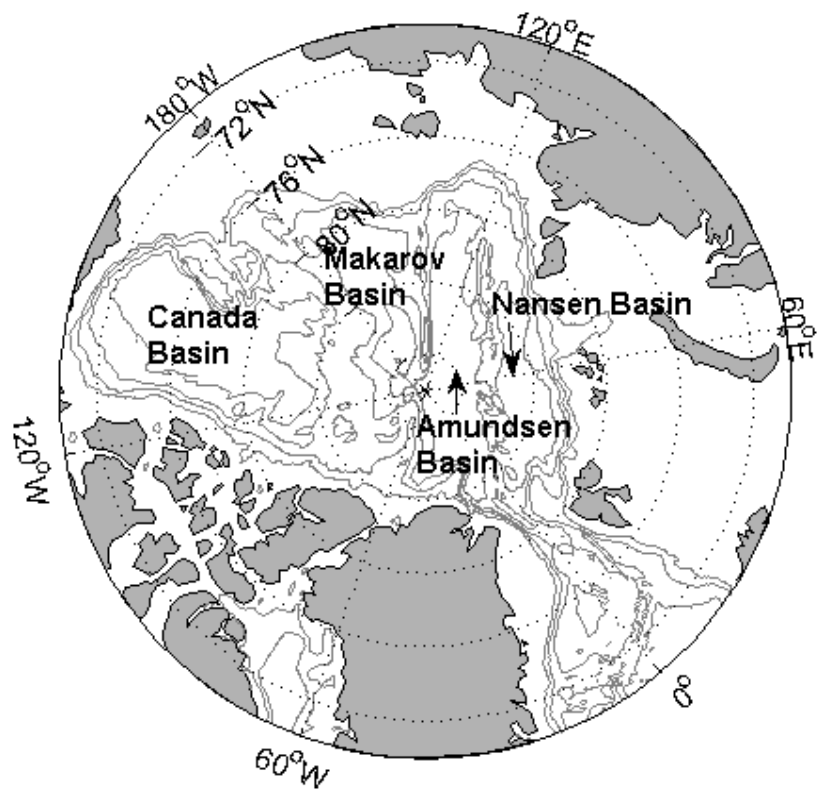

Figure 2. The basins of the Arctic Ocean.

Unfortunately, it was difficult to control which stations were included in the crossover so that all stations chosen were in the same basin. Also, keeping the crossover radius not too large often made the number of stations so few that no standard deviation could be calculated. Due to this, the crossover results will not be discussed. It is noteworthy that the crossover results did not contradict the basin average results.

Trying another approach for the investigations, a regional multi-linear regression (MLR) was applied for each parameter (the MLR was applied to data deeper than 2500). For each basin, data from all the cruises were used to create a multi-linear regression function for a specific variable. The values calculated from the MLRs for each sample were then compared to the measured values. If the MLR supported the evidence from the basin averages we assumed that there is an offset and the magnitude then determines if a correction is needed. However, care must be taken when choosing the predictor variables of the MLR so that none of these are biased. A number of different MLRs were used for each variable and basin. Since we are not investigating the influence of one individual predictor variable, the MLR can consist of dependent variables. The following are examples of MLRs that were used, but other MLRs were run for every test to check that there was no bias in the results due to an offset in a predictor variable (note: the $\alpha_{1 \ldots n}$-coefficients are individual for each regression):

$$
\begin{aligned}
& \mathrm{TCO}_{2}=\alpha_{1}+\alpha_{2} \text { Salinity }+\alpha_{3} \text { Theta }+\alpha_{4} \mathrm{NO}_{3}+\alpha_{5} \mathrm{Si}+\alpha_{6} \mathrm{AOU} \\
& \mathrm{TCO}_{2}=\alpha_{1}+\alpha_{2} \text { Salinity }+\alpha_{3} \text { Theta }+\alpha_{4} \mathrm{PO}_{4}+\alpha_{5} \mathrm{Si}+\alpha_{6} \mathrm{AOU} \\
& \mathrm{TA}=\alpha_{1}+\alpha_{2} \text { Salinity }+\alpha_{3} \text { Theta }+\alpha_{4} \mathrm{PO}_{4}+\alpha_{5} \mathrm{Si} \\
& \mathrm{TA}=\alpha_{1}+\alpha_{2} \text { Salinity }+\alpha_{3} \text { Theta }+\alpha_{4} \mathrm{NO}_{3}+\alpha_{5} \mathrm{Si}
\end{aligned}
$$

Examples of MLRs for oxygen and nutrients (here also other sets of parameters were used):

$$
\begin{aligned}
& \mathrm{O}_{2}=\alpha_{1}+\alpha_{2} \text { Salinity }+\alpha_{3} \text { Theta }+\alpha_{4} \mathrm{NO}_{3}+\alpha_{5} \mathrm{Si} \\
& \mathrm{O}_{2}=\alpha_{1}+\alpha_{2} \text { Salinity }+\alpha_{3} \text { Theta }+\alpha_{4} \mathrm{PO}_{4} \\
& \mathrm{Si}=\alpha_{1}+\alpha_{2} \text { Salinity }+\alpha_{3} \text { Theta }+\alpha_{4} \mathrm{PO}_{4}+\alpha_{5} \mathrm{AOU} \\
& \mathrm{NO}_{3}=\alpha_{1}+\alpha_{2} \text { Salinity }+\alpha_{3} \text { Theta }+\alpha_{4} \mathrm{Si}+\alpha_{5} \mathrm{AOU} \\
& \mathrm{PO}_{4}=\alpha_{1}+\alpha_{2} \text { Salinity }+\alpha_{3} \text { Theta }+\alpha_{4} \mathrm{NO}_{3}+\alpha_{5} \mathrm{Si}
\end{aligned}
$$

For the evaluation of the MLRs, the adjusted $R^{2}$-value is checked as well as the root mean square error and the residuals. 


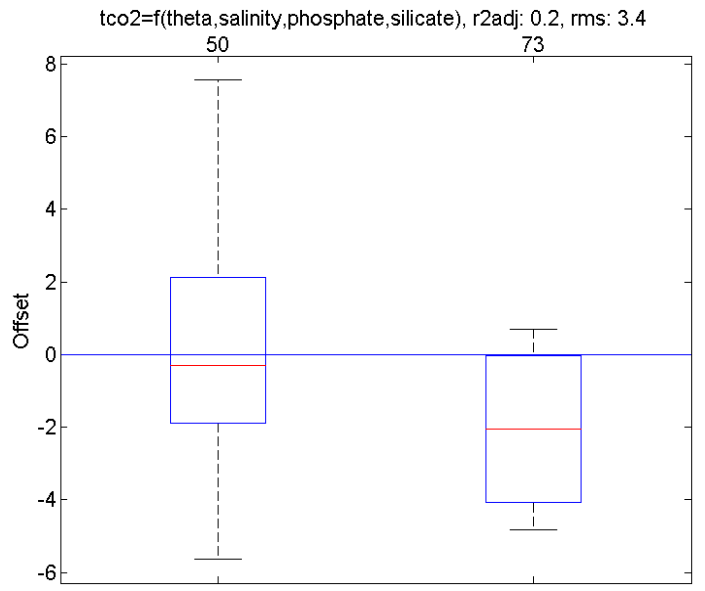

Figure 3. MLR results for $\mathrm{TCO}_{2}$ in the Canada Basin (offsets in $\left.\mu \mathrm{mol} \mathrm{kg}{ }^{-1}\right)$. The figure contains the predictor function at the top, followed by the adjusted $R^{2}$-value and the root mean square error. The boxes contain lines at the median and upper and lower quartiles. The whiskers extend 1.5 times the interquartile range of the sample. Values outside the whiskers are considered outliers and are marked by red + .

\section{MLR-results}

For an adjustment to be made, it was determined that the offset should be greater than $4 \mu \mathrm{mol}$ for $\mathrm{TCO}_{2}, 6 \mu \mathrm{mol}$ for TA, $2 \%$ for nutrients and oxygen and 0.01 for salinity. For salinity none of the deep-water averages showed any differences larger than 0.01 for any of the cruises in the same basin and salinity was not run with MLRs. The figures in this section showing the MLR results have the offset on the y-axis and the number on the $\mathrm{x}$-axis corresponds to the Cruise \# (see Tables 1 or 2) for each cruise involved in the MLR.

\section{$3.1 \mathrm{TCO}_{2}$}

\subsubsection{The Canada Basin}

The cruises that had $\mathrm{TCO}_{2}$ measurements in the deep-water in the Canada Basin were: 18SN19970924 (Cruise \#50) and 32H120020718 (73). Both cruises used Certified Reference Materials (CRMs), however the $\mathrm{TCO}_{2}$ samples for $32 \mathrm{H} 120020718$ were poisoned and stored for analyses at shore. The deep-water averages of $\mathrm{TCO}_{2}$ show a $5 \mu \mathrm{mol}$ offset between the cruises. The results from the MLRs showed only smaller offsets. Runs without AOU were also made since the deep-water averages of oxygen showed a discrepancy (Fig. 3). Those results showed a potential offset between the cruises of $\sim 2-3 \mu \mathrm{mol}$. Since it is difficult to say which of the cruises is offset as compared to the other and $32 \mathrm{H} 120020718$ only had three stations in deep-water and had stored samples, as well as the offset being just on the limit, no adjustment is advised.

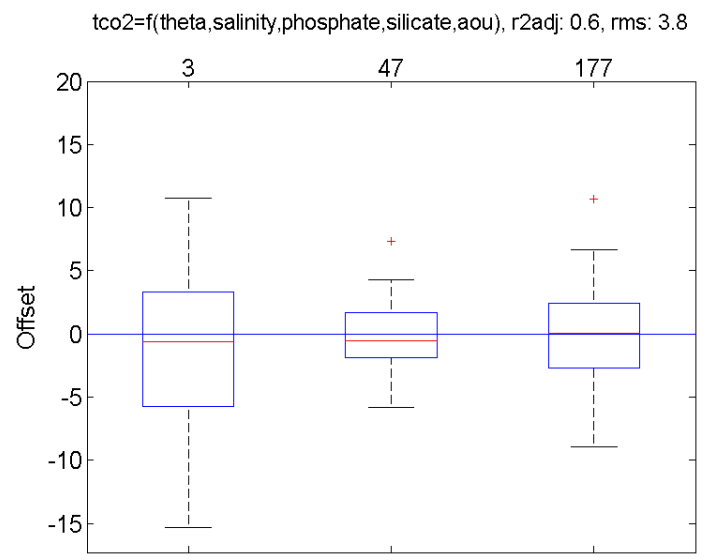

Figure 4. MLR results for $\mathrm{TCO}_{2}$ in the Amundsen Basin (offsets in $\mu \mathrm{mol} \mathrm{kg}{ }^{-1}$ ).

\subsubsection{The Makarov Basin}

The following cruises were part of the MLR in the Makarov Basin: 06AQ19960712 (3), 18SN19940724 (47) and 77DN19910726 (177). Of these 77DN19910726 did not have CRMs. From the deep averages the 06AQ19960712 cruise seems quite a bit lower than the others $(\sim 10 \mu \mathrm{mol})$. This is not supported in the MLR functions using all three cruises, however when using 18SN19940724 and 77DN19910726 as master cruises for the MLRs the offset increases. As the MLRs are inconclusive and 06AQ19960712 has a greater number of stations in the Amundsen and Nansen basins no adjustments will be suggested at this point.

\subsubsection{The Amundsen Basin}

Cruises included in the Amundsen Basin MLR: 06AQ19960712 (3), 18SN19940724 (47) and 77DN19910726 (177) (no CRMs). The results show no significant offsets in the MLRs (Fig. 4) even though the spread is quite large, either when all cruises are used in the MLR or when 18SN19940724 and 77DN19910726 are used as master cruises for the MLR.

\subsubsection{The Nansen Basin}

Cruises included in the Nansen Basin MLRs were: 06AQ19930806 (2), 06AQ19960712 (3), 18SN19940724 (47), 77DN19910726 (177) and 77DN20020420 (179). The deep-water averages for 77DN20020420 and 06AQ19930806 suggested that these cruises had lower $\mathrm{TCO}_{2}$ than the others; this is only in part shown in the MLR (Fig. 5) with the 77DN20020420 cruise being somewhat lower than the others. For this cruise CRMs were used and it also had stations in the deep Greenland Sea, so any corrections would also have to take into account how it fits the other Nordic Seas cruises. Olsen (2009) investigated the 


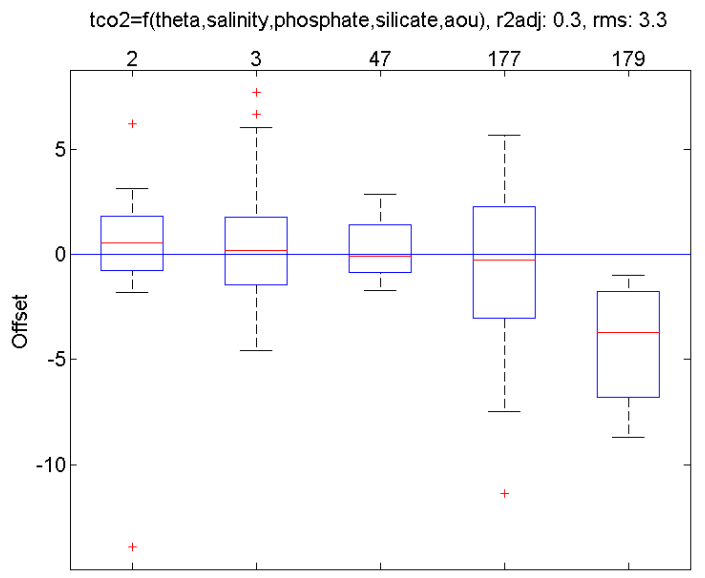

Figure 5. MLR results for $\mathrm{TCO}_{2}$ in the Nansen Basin (offsets in $\mu \mathrm{mol} \mathrm{kg}{ }^{-1}$ ).

$\mathrm{TCO}_{2}$ data in the Nordic Seas and did not find an offset large enough to validate an adjustment for this cruise. Therefore no adjustment of the $\mathrm{TCO}_{2}$ data from 77DN20020420 was made.

06AQ19930806 was also excluded in a test run to see the impact on the other cruises $\left(\mathrm{O}_{2}\right.$ and $\mathrm{NO}_{3}$ seemed to be off when considering the deep-water averages), but only small differences resulted from this. The offset suggested by the deep-water averages for 18SN19940724 is not evident in any of the regional MLRs. Since the possible offset found in the Makarov Basin for 06AQ19960712 was not validated in the results for the Amundsen and Nansen basins where the major part of the stations were located, no adjustment was made.

\section{$3.2 \mathrm{TA}$}

\subsubsection{The Canada Basin}

The deep-water averages of TA in the Canada Basin only contain 18SN19970924. CRMs were used on this cruise and the value seems reasonable. No correction of TA is suggested.

\subsubsection{The Makarov Basin}

Included cruises in the Makarov Basin: 06AQ19960712 (3), 18SN19940724 (47) and 77DN19910726 (177). Deep-water averages show a large discrepancy in alkalinity. The MLRs support this (e.g. Fig. 6) especially with regards to the high offsets in the 18SN1994072 data. These cruises are also included in other basins so the correction must also depend on the results from the Amundsen and the Nansen Basin and will be discussed at the end of the TA results.

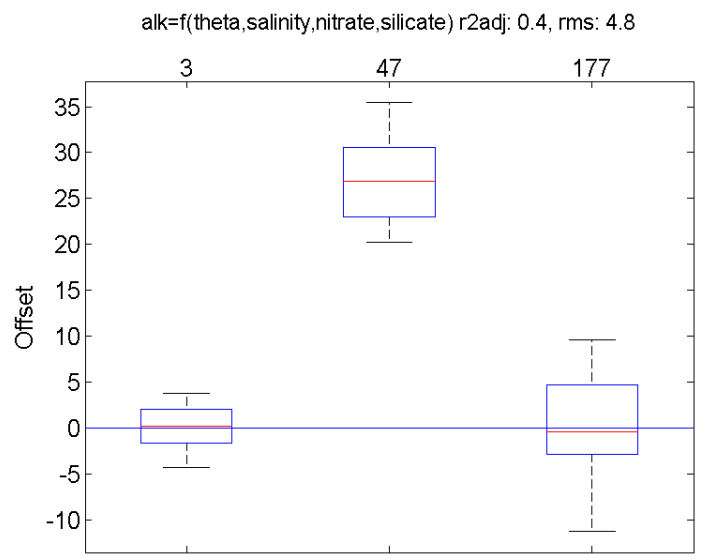

Figure 6. MLR results for TA in the Makarov Basin (offsets in $\mu \mathrm{mol} \mathrm{kg}{ }^{-1}$ ).

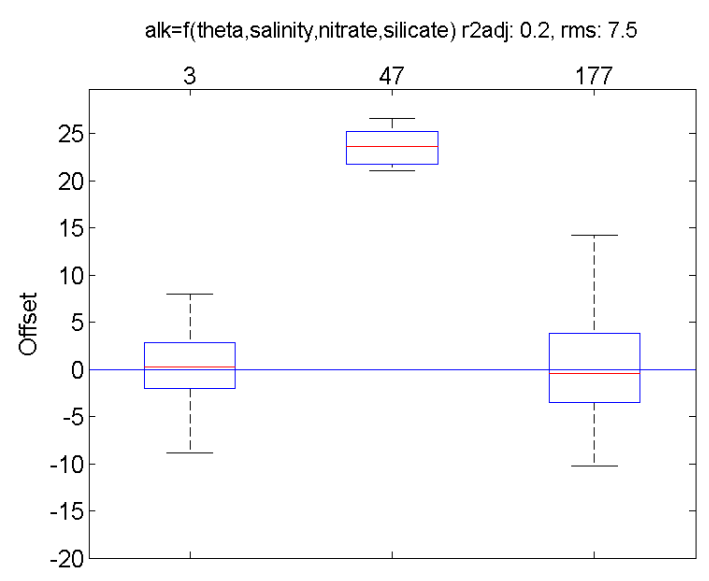

Figure 7. MLR results for TA in the Amundsen Basin (offsets in $\mu \mathrm{mol} \mathrm{kg}{ }^{-1}$ ).

\subsubsection{The Amundsen Basin}

Cruises included in the Amundsen Basin: 06AQ19960712 (3), 18SN19940724 (47) and 77DN19910726 (177). The results are very similar to those found in the Makarov Basin, although there is an even larger spread in 77DN19910726 and 06AQ19960712 data and a decrease in the MLR fit (Fig. 7).

\subsubsection{The Nansen Basin}

Cruises included in the Nansen Basin: 18SN19940724 (47), 77DN19910726 (177) and 77DN20020420 (179). 06AQ19960712 had a breakdown of the TA system and did not have TA data in the deep Nansen Basin. The MLRs still suggest an offsets for 18SN19940724.

\subsubsection{Discussion}

TA data for 77DN19910726 seem lower than the other cruises in the Makarov and Amundsen Basins when looking 
at the deep-water averages. No CRMs were used on this cruise which suggests that a correction is not surprising. Considering that most of the stations of this cruise were located in the Amundsen and Nansen Basin and only a few stations in the Makarov Basin it makes more sense to trust the Eurasian Basin results. Also, TA data were quite scattered in the deep-waters in the Makarov Basin. The MLRs in the Eurasian Basin do not support the differences found in the deep-water averages, even if there is a large spread in 77DN19910726 data as seen in Figs. 6 and 7. In conclusion, no correction to TA data is suggested for this cruise.

For the 18SN19940724 cruise deep-water averages suggest that this cruise is almost $30 \mu \mathrm{mol}$ higher than e.g. 06AQ19960712. This is supported in the MLRs giving positive offsets between $22-30 \mu \mathrm{mol} \mathrm{kg}{ }^{-1}$. In conclusion it is most likely that 18 SN19940724 has a positive offset in TA of about $24 \mu \mathrm{mol} \mathrm{kg}{ }^{-1}$.

\section{$3.3 \mathrm{pH}$}

Only two cruises had measured $\mathrm{pH}$ (and, since they also measured TA and $\mathrm{TCO}_{2}$ on the same cruise, overdetermined the carbonate system): 77DN20020420 and 06AQ19960712. By doing "round-calculations", i.e. using $\mathrm{TA}$ and $\mathrm{TCO}_{2}$ to calculate $\mathrm{pH}, \mathrm{TCO}_{2}$ and $\mathrm{pH}$ to calculate TA and TA and $\mathrm{pH}$ to calculate $\mathrm{TCO}_{2}$ and then comparing the measured parameter to the calculated, it is possible to get an idea of whether any of the parameters are offset. This was done for the cruises mentioned above (using CO2SYS by Lewis and Wallace, with the constants from Mehrbach et al. (1973) refit by Dickson and Millero, 1987). The results show a difference in TA of about $3 \mu \mathrm{mol} \mathrm{kg}{ }^{-1}$ between measured and calculated and the same for DIC. $\Delta \mathrm{pH}$ has an average of 0.008 and in view of this no corrections of $\mathrm{pH}$ is suggested. Velo et al. (2009) evaluated the $\mathrm{pH}$ data in the CARINA data set, but since there were only three cross-overs for $\mathrm{pH}$ in the Arctic Ocean data, the authors drew no conclusions regarding possible adjustments.

\section{$\begin{array}{ll}3.4 & \mathrm{O}_{2}\end{array}$}

For oxygen a clear offset in the deep-water averages $(>2 \%$ from the average) was seen in one cruise in the Nansen Basin (06AQ19930806) and a smaller offset of just over $2 \%$ in the Canada Basin (between 18SN19970924 and 32H120020718).

\subsubsection{The Canada Basin}

The following cruises were part of the MLR in the Canada Basin: 18SN19970924 (50) and 32H120020718 (73). The results did not differ substantially between different predictor variables; the largest offset between the cruises was only about $2 \%$. Since the deep-water averages and the MLR are on the limit, the suggestion is not to adjust.

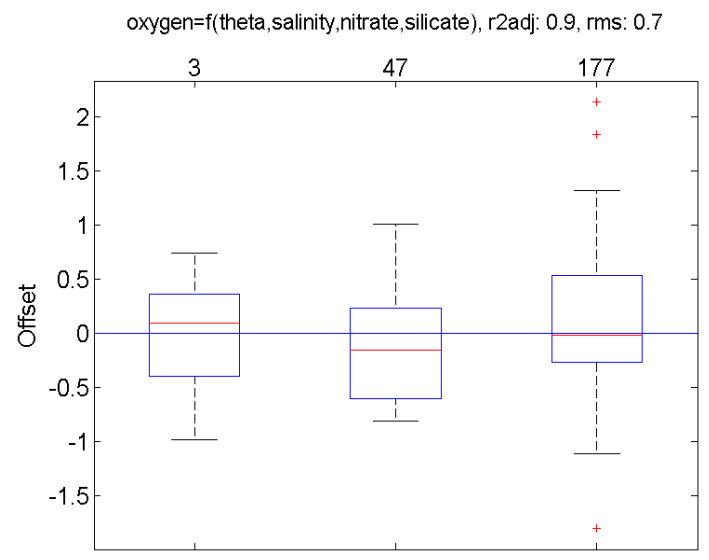

Figure 8. MLR results for $\mathrm{O}_{2}$ in the Makarov Basin (offsets in $\mu \mathrm{mol} \mathrm{kg}{ }^{-1}$ ).

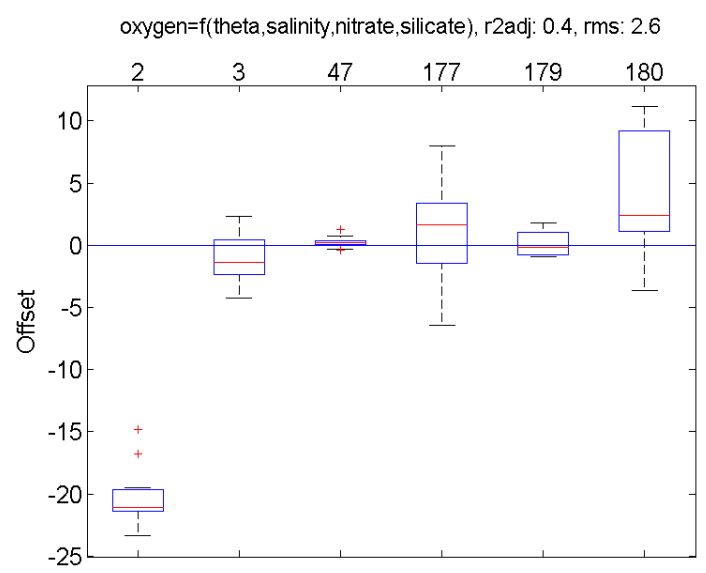

Figure 9. MLR results for $\mathrm{O}_{2}$ in the Nansen Basin (offsets in $\mu \mathrm{mol} \mathrm{kg}{ }^{-1}$ ).

\subsubsection{The Makarov and Amundsen Basins}

Oxygen MLRs for the Makarov Basin (Fig. 8) and Amundsen Basin were run, although no results diverged from the conclusions of the deep-water averages.

\subsubsection{The Nansen Basin}

The following cruises were part of the MLR in the Nansen Basin: 06AQ19930806 (2), 06AQ19960712 (3), 18SN19940724 (47), 77DN19910726 (177), 77DN20020420 (179) and 77YM19800811 (180).

Figure 9 shows an offset for 06AQ19930806, which was also indicated in the deep-water averages. However, 77 YM19800811 is also somewhat offset. Looking closer at 06AQ19930806 and 77YM19800811 and the predictor variables, the 06AQ19930806 cruise seems to have a lower deepwater average in $\mathrm{NO}_{3}$ as well as oxygen and 77YM19800811 seem to be low in $\mathrm{NO}_{3}$ and $\mathrm{PO}_{4}$, while the deep-water average for oxygen is not far off from the other cruises. Changing 


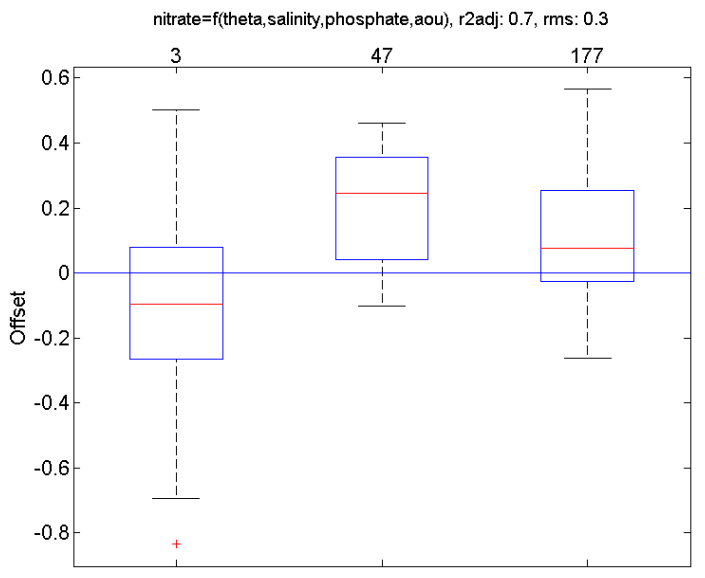

Figure 10. MLR results for $\mathrm{NO}_{3}$ in the Makarov Basin (offsets in $\mu \mathrm{mol} \mathrm{kg}{ }^{-1}$ ).

the predictor variables to exclude $\mathrm{NO}_{3}$ and also other nutrients was done. The results were similar in the sense that the 06AQ19930806 cruise showed an offset of 14-23 $\mu \mathrm{mol}$. 77 YM19800811 varies between having a small offset $(>2 \%)$ to having no offset. Excluding $\mathrm{NO}_{3}$ keeps 77YM19800811 within the limits and it is likely that this seems to be a question about the $\mathrm{NO}_{3}$ being too low rather than the oxygen being too high for this cruise.

\subsection{Nutrients}

\subsubsection{The Canada Basin}

For the Canada Basin the deep-water averages for $\mathrm{NO}_{3}, \mathrm{PO}_{4}$ and $\mathrm{Si}$ are not significantly $(>2 \%)$ offset between the different cruises, as can be seen in Table 2. MLRs in this basin support this. Testing different sets of predictor variables such as $\mathrm{AOU} / \mathrm{PO}_{4}, \mathrm{AOU} / \mathrm{Si}$ or $\mathrm{Si} / \mathrm{PO}_{4}$ or running MLRs of the other nutrients yielded the same results.

\subsubsection{The Makarov Basin}

In the Makarov Basin deep-water averages, the $\mathrm{NO}_{3}$ concentration for 06AQ19960712 is quite a bit lower than the other cruises in this basin. This is also seen in the Amundsen Basin. In the MLR it is instead 18SN19940724 that shows up a little bit on the high side (Fig. 10). Using other predictor variables does not give evidence either for a large enough negative offset for 06AQ19960712 or positive offset for 18 SN19940724 to justify a correction of data. The P:N ratios for these cruises are the same: 1:14. The Si concentrations in the deep-water differ quite a bit, however when running MLRs, no conclusive offsets are found.

\subsubsection{The Amundsen Basin}

In the Amundsen Basin again the 06AQ19960712 cruise has a lower deep-water average of $\mathrm{NO}_{3}$ than the others and the

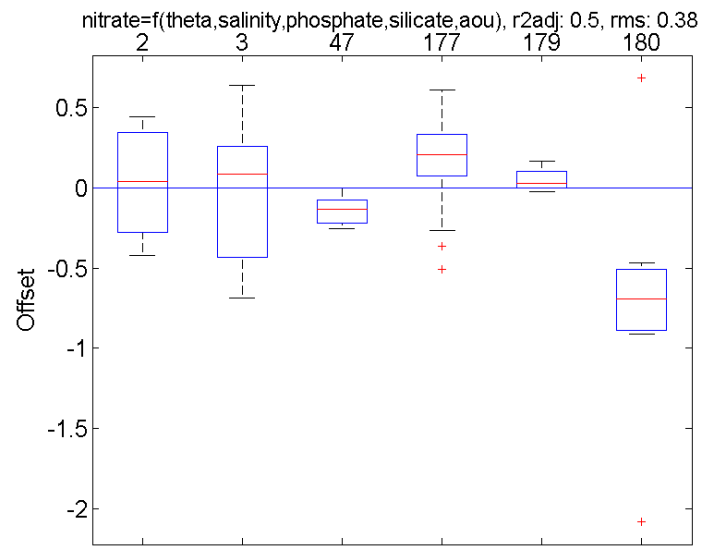

Figure 11. MLR results for $\mathrm{NO}_{3}$ in the Nansen Basin (offsets in $\mu \mathrm{mol} \mathrm{kg}{ }^{-1}$ ).

Si values are quite varied. The results are quite similar to the Makarov runs. No conclusive offsets.

\subsubsection{The Nansen Basin}

In the Nansen Basin the clearest offsets in the deep-water nutrient averages are the $\mathrm{NO}_{3}$ average of the 06AQ19930806 cruise, the $\mathrm{Si}$ average of the $18 \mathrm{SN} 19940724$ cruise and the $\mathrm{NO}_{3}$ and $\mathrm{PO}_{4}$ averages of the 77YM19800811 cruise. The latter cruise also has rather low Si concentrations. Although this can be explained by the fact that the deep stations are close to Fram Strait and the deep-water concentrations of $\mathrm{Si}$ seem to decrease in this area this does not explain the very low $\mathrm{NO}_{3}$ values. In Fig. 11 the offset in $\mathrm{NO}_{3}$ for 77 YM19800811 is quite clear and changing the predictor variables does not change the offset significantly.

Since 77YM19800811 does not contain any carbon parameters in the CARINA data product, has few deep stations in the Arctic Ocean proper and is clearly offset in $\mathrm{NO}_{3}$ and $\mathrm{PO}_{4}$, the suggestion is to exclude this cruise. Figure 11 does not show an offset for $\mathrm{NO}_{3}$ from the 06AQ19930806 cruise. However, when removing $\mathrm{AOU}$ as a predictor variable, since it was earlier determined to be offset for 06AQ19930806, the result show a clear negative offset of $\mathrm{NO}_{3}$ for 06AQ19930806. Changing predictor variables between $\mathrm{PO}_{4}$ and $\mathrm{Si}$ does not change this result. Therefore the suggestion is to adjust $\mathrm{NO}_{3}$ for the 06AQ19930806 cruise. An MLR where the AOU was calculated with adjusted oxygen values for 06AQ19930806 was created to see if the offset in nitrate would show and the result is shown in Fig. 12 where the nitrate is clearly offset. The high $\mathrm{Si}$ in the deep-water average for 18SN19940724 does show up to some extent in the MLR, but since this is not the case for the other basins and there are only a few stations for 18SN19940724 in the Nansen Basin there is no suggestion to adjust. 


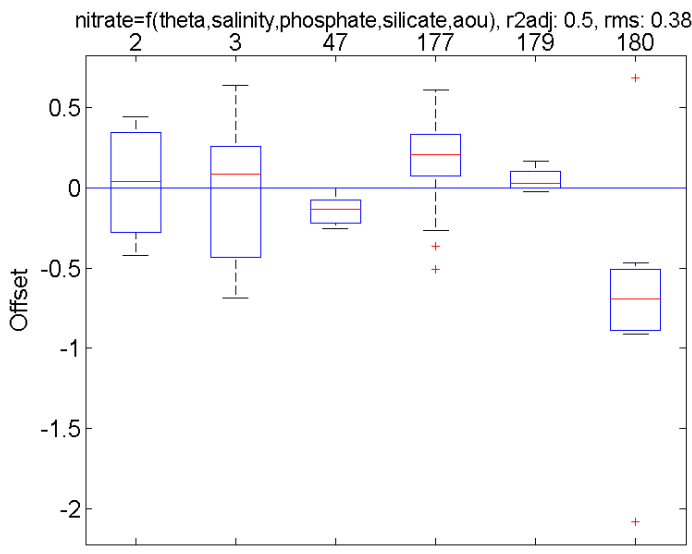

Figure 12. MLR results for $\mathrm{NO}_{3}$ in the Nansen Basin (offsets in $\mu \mathrm{mol} \mathrm{kg}{ }^{-1}$ ), calculated using adjusted AOU for 06AQ19930806.

\section{Applied adjustments}

$\mathrm{TCO}_{2}$ : No adjustments.

TA: 18 SN19940724 is offset by $24 \mu \mathrm{mol} \mathrm{kg}^{-1}$ and was adjusted downwards by this amount in the data product.

pH: No adjustments.

$\mathrm{O}_{2}$ : 06AQ19930806 was adjusted upwards by $7 \%$ in the data product.

Nutrients: Excluded 77YM19800811 from the synthesis, and $\mathrm{NO}_{3}$ concentrations for 06AQ19930806 were adjusted upwards by $5 \%$ in the data product.

Salinity: No adjustments.

Acknowledgements. This would not have been possible without the scientists and crews at sea spending countless hours and great effort to bring high quality data back from the Arctic Ocean. Also great thanks to the PIs responsible for sharing the data. The EU through IP CARBOOCEAN, contract no. 511176. Additional support provided as follows for: R,M. Key (grant NANA08OAR4320752 and NA08OAR4310820), X. Lin; NOAA grant NA08OAR4310820, A. Olsen (Research Council of Norway grant 178167/S30 (A-CARB)).

Edited by: T. Tanhua

\section{References}

Dickson, A. G. and Millero, F. J.: A comparison of the equilibrium constants for the dissociation of carbonic acid in seawater media, Deep-Sea Res., 34, 1733-1743, 1987.

Jeansson, E., Olsson, K. A., Tanhua, T., and Bullister, J. L.: Nordic Seas and Arctic Ocean CFC data in CARINA, Earth Syst. Sci. Data Discuss., 2, 493-536, 2009, http://www.earth-syst-sci-data-discuss.net/2/493/2009/.

Lewis, E. and Wallace, D. W. R.: Program Developed for $\mathrm{CO} 2$ Systems Calculations. ORNL/CDIAC-105, Carbon Dioxide Information Analysis Centre, Oak Ridge National Laboratory, US Department of Energy, Oak Ridge, Tennessee, 1998.

Mehrbach, C., Culbertson, C. H., Hawley, J. E., and Pytkowicz, R. M.: Measurement of the apparent dissociation constants of carbonic acid in seawater at atmospheric pressure, Limnol. Oceanogr., 18, 897-907,1973.

Olsen, A.: Nordic Seas total dissolved inorganic carbon data in CARINA, Earth Syst. Sci. Data, 1, 35-43, 2009, http://www.earth-syst-sci-data.net/1/35/2009/.

Olsen, A., Key, R. M., Jeansson, E., Falck, E., Olafsson, J., van Heuven, S., Skjelvan, I., Omar, A. M., Olsson, K. A., Anderson, L. G., Jutterström, S., Rey, F., Johannessen, T., Bellerby, R. G. J., Blindheim, J., Bullister, J. L., Pfeil, B., Lin, X., Kozyr, A., Schirnick, C., Tanhua, T., and Wallace, D. W. R.: Overview of the Nordic Seas CARINA data and salinity measurements, Earth Syst. Sci. Data, 1, 25-34, 2009, http://www.earth-syst-sci-data.net/1/25/2009/.

Tanhua, T., van Heuven, S., Key, R. M., Velo, A., Olsen, A., and Schirnick, C.: Quality control procedures and methods of the CARINA database, Earth Syst. Sci. Data Discuss., 2, 205-240, 2009, http://www.earth-syst-sci-data-discuss.net/2/205/2009/.

Velo, A., Pérez, F. F., Lin, X., Key, R. M., Tanhua, T., de la Paz, M., van Heuven, S., Jutterström, S., and Ríos, A. F.: CARINA data synthesis project: $\mathrm{pH}$ data scale unification and cruise adjustments, Earth Syst. Sci. Data Discuss., 2, 421-475, 2009, http://www.earth-syst-sci-data-discuss.net/2/421/2009/. 